\title{
Review \\ Mammary epithelial cell transformation: insights from cell culture and mouse models
}

\author{
Goberdhan Dimri ${ }^{1}$, Hamid Band ${ }^{2}$ and Vimla Band ${ }^{1}$
}

\begin{abstract}
1'Division of Cancer Biology, Department of Medicine, ENH Research Institute, and Robert H Lurie Comprehensive Cancer Center, Feinberg School of Medicine, Northwestern University, Evanston, Illinois, USA

${ }^{2}$ Division of Molecular Oncology, Department of Medicine, ENH Research Institute, and Robert H Lurie Comprehensive Cancer Center, Feinberg

School of Medicine, Northwestern University, Evanston, Illinois, USA
\end{abstract}

Corresponding author. Vimla Band, v-band@northwestern.edu

Published: 3 June 2005

This article is online at http://breast-cancer-research.com/content/7/4/171

(c) 2005 BioMed Central Ltd
Breast Cancer Research 2005, 7:171-179 (DOI 10.1186/bcr1275)

\section{Introduction}

More than $80 \%$ of adult human cancers are carcinomas, tumors originating from malignant transformation of epithelial cells. However, much of our understanding of oncogenic transformation comes from fibroblast transformation systems. Breast cancer is the second leading cause of cancer-related deaths among women in the USA [1]. The vast majority of breast cancers are carcinomas that originate from cells lining the milk-forming ducts of the mammary gland (for review [2]). Deliberate transformation of these cells provides a practical window into human epithelial oncogenesis. Malignant transformation represents a complex multistep process in which genetic, environmental, and dietary factors together are thought to alter critical cell growth regulatory pathways resulting in uncontrolled proliferation, which is a hallmark of tumorigenesis $[3,4]$. Understanding the nature of these cellular pathways is of central importance in cancer biology.

The growth of normal human mammary epithelial cells (HMECs), which include luminal, myoepithelial and/or basal cells (described below), is tightly controlled. These cells grow for a finite life span and eventually senesce (for review [5-7]). Both cell culture and mouse models have provided evidence that essential initial steps in tumorigenesis involve the loss of senescence checkpoints and immortalization, which allow a cell to grow indefinitely and to go through further oncogenic steps, resulting in fully malignant behavior. In addition, cell culture model systems have identified a number of genes whose alterations are involved in HMEC immortalization and thereby have provided significant insights into the biology of early breast cancer $[5,7,8]$. Use of oncogene combinations has allowed researchers to create cell culture models of full HMEC transformation, thereby illuminating the process of

ASMA $=\alpha$-smooth muscle actin; CDK $=$ cyclin-dependent kinase; $C O X=$ cyclo-oxygenase; $E R=$ estrogen receptor; ESA $=$ epithelial-specific antigen; HMEC = human mammary epithelial cell; HPV = human papillomavirus; hTERT = catalytic subunit of human telomerase; PD = population doubling; Ral-GEF = Ral guanine nucleotide exchange factor; TDLU = terminal ductal-lobular unit. 
breast cancer progression [9-11]. Additional insights have come from mouse models, using transgenic overexpression of oncogenesis-promoting genes and deletion of tumor suppressor genes, which often produce breast adenocarcinomas that closely resemble human breast cancers.

Studies using cell culture transformation models have pointed to the existence of HMEC subtypes with distinct susceptibilities to oncogenesis by different oncogenes $[5,8]$. Remarkably, direct cDNA microarray profiling of human breast cancers has led to similar insights, identifying multiple subtypes of human breast cancer with distinct outcomes; phenotypic and genotypic characteristics of these breast cancer subtypes point to their possible origin from specific subtypes of HMECs, such as basal or luminal cells [12]. Finally, cell culture and mouse model systems have begun to identify mammary stem cells that may provide progenitors for oncogenic transformation [13] and have led to an appreciation of the microenvironment for oncogenesis $[14,15]$.

Thus, studies conducted over the past several years have established the importance of HMEC transformation models to our understanding of the pathways that control normal mammary cell growth, development, and oncogenesis. However, many challenges remain, including the identification of mammary cell subtypes or oncogenic strategies that result in cancers that resemble naturally occurring human breast cancers, and translation of new research to devise more specific diagnostic and treatment strategies for different subtypes of breast cancer.

\section{Mammary gland and various epithelial cell subtypes}

The mammary gland consists of a branching ductal system that ends in terminal ducts with their associated acinar structures, termed the terminal ductal-lobular units (TDLUs), together with interlobular fat and fibrous tissue [16,17]. Most breast cancers arise in the TDLU (Fig. 1). Unlike other epithelial cancers, such as that of colon, different stages of breast cancer are not clearly defined. However, it is clear that benign stages (such as typical and atypical hyperplasia), noninvasive cancers (such as carcinoma in situ - ductal or lobular), and invasive cancers (such as invasive ductal or lobular carcinomas) do exist. Additionally, multiple types of in situ carcinomas, such as solid, cribiform, papillary and comedo types, have been reported and it is possible that these represent tumors originating from different epithelial subtype $[16,17]$.

Histological examination of TDLU reveals two major types of cells: inner secretory luminal cells and outer contractile myoepithelial cells (Fig. 1). In addition to luminal and myoepithelial cells, there is emerging evidence that basal cells (presumed to be the progenitor for myoepithelial cells) and stem cells exist in the TDLU $[17,18]$. Until recently it was
Figure 1

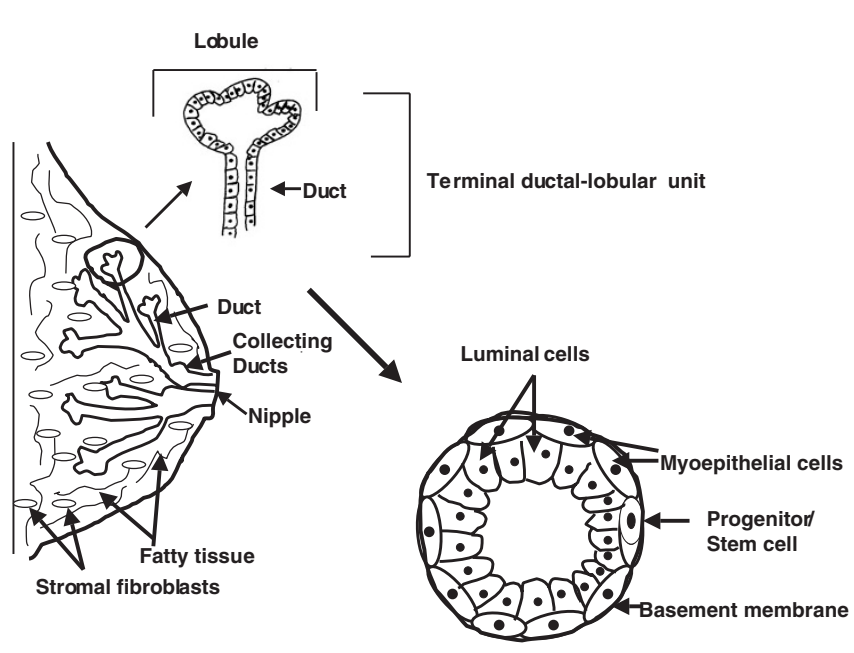

Structure of the mammary gland. Terminal ductal-lobular unit (TDLU), composed of ductal cells, is the unit thought to be the origin of most breast cancer. The stroma is composed of fatty tissue (adipocytes) and fibroblasts. Also shown are the two primary types of cells in normal ducts: outer contractile myoepithelial and inner columnar luminal cells. A putative progenitor/stem cell is also indicated.

luminal epithelial cells [2]. This was based on the keratin expression and other phenotypic markers of cultured tumor cell lines, mostly derived from metastatic lesions [2]. Unfortunately, the great majority of primary breast tumors have proved difficult to establish in cultures, either on plastic or as three-dimensional cultures [5-7,19-21]. However, recent molecular profiling studies clearly show the existence of multiple subtypes of breast cancers probably originating from luminal, basal, and possibly stem cell compartments [12] (described below in detail).

\section{Culturing of various epithelial cell subtypes}

For more than two decades, various investigators have attempted to develop cell culture models that lead to isolation of breast cancer cells resembling those found in human breast cancers. In order to establish such models, it was essential to culture normal HMECs. In 1980s, work from several laboratories showed that normal HMECs could be cultured in cell culture [22,23] (for review $[2,5,7]$ ).

In our laboratory we defined a medium, termed DFCl-1, that helped us to establish and culture normal and some primary breast cancers under identical conditions [20]. However, in general the difficulty in establishing primary tumor cells in cell culture has persisted. Notably, early cultures derived from reduction mammoplasty or mastectomy specimens exhibit considerable heterogeneity (with multiple cell types - luminal, stem cells, basal and myoepithelial cells) and grow for three to four passages or about 15-20 population doublings (PDs), and then senesce (Figs 2 and 3) [5-7]. The senescence in these cells is also termed as MO stage [24]. 
Figure 2

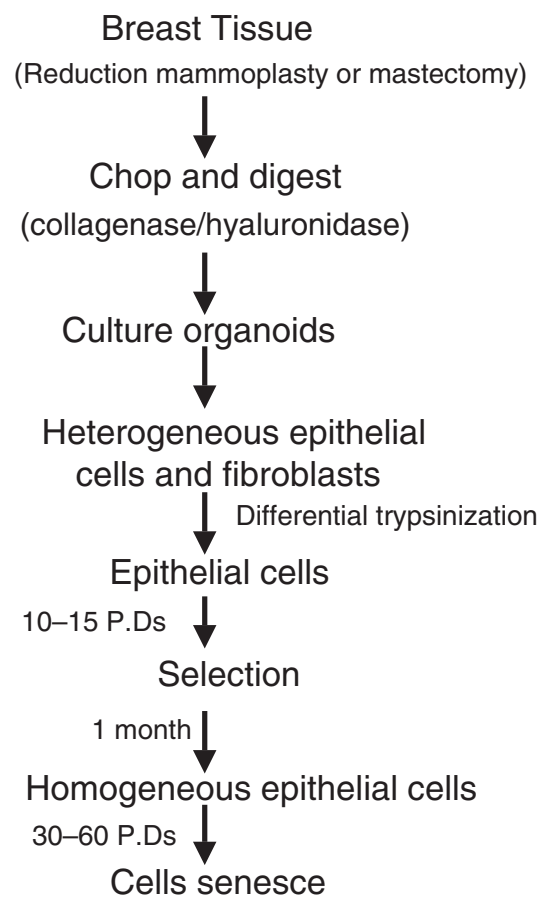

Establishment of mammary epithelial cells from reduction mammoplasty/mastectomy specimens. The tissue is chopped, digested with collagenase and hyaluronidase, and plated in medium as organoids. Over a week or so, multiple types of epithelial cells and fibroblasts emerge; fibroblasts are removed by differential trypsinization (fibroblasts are loosely attached), remaining epithelial cells grow for 10-15 population doublings (PDs) followed by senescence of the majority of cells. Occasionally, an homogenous population of cells emerges that continue to proliferate for an additional 30-60 PDs, and eventually these cells also senesce (this step is referred to as agonescence).

However, in some cases (not always) an occasional homogenous cell population emerges that continue to grow further for 30-60 PDs (Figs 2 and 3) [5-7] before senescence occurs (also called agonescence, described below) [25]. This process of emergence of cells that are able to proliferate for extended periods is also known as self-selection; before selection the cells are termed preselection cells, whereas those that emerge after selection are called postselection cells. The keratin profile of preselection cells (K-5, K-6, K-7, $\mathrm{K}-14, \mathrm{~K}-17, \mathrm{~K}-18$ and $\mathrm{K}-19$ positive) $[8,19,26]$ suggests the existence of both luminal and basal (myoepithelial) cells. However, postselection cells generally exhibit a loss of expression of K-19 but retain the expression of all other keratins $[8,18,25]$. These cells also express $\alpha$-smooth muscle actin (ASMA), suggesting that these may be of myoepithelial origin. Further development of cell sorting techniques and chemically defined media have helped in culturing of luminal and progenitor epithelial cells $[14,27]$ (described below in detail).

It has also been reported that postselection cells lose the expression of p16 INK4a, a cyclin-dependent kinase (CDK)
Figure 3 (a)

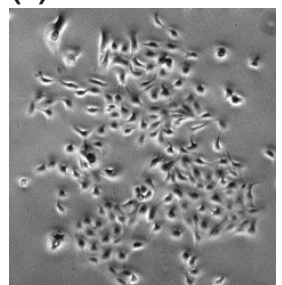

(b)

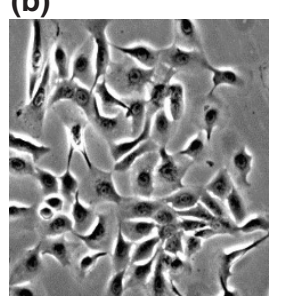

(c)

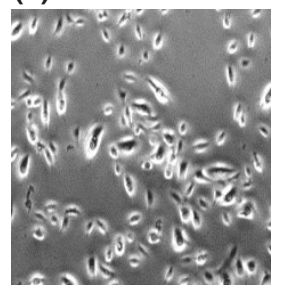

(d)

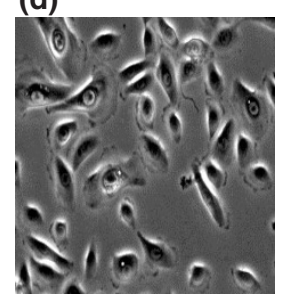

(e)

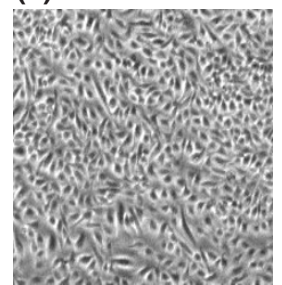

(f)

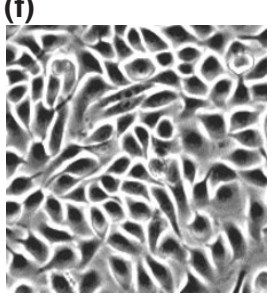

Morphological heterogeneity of cells before and after selection. (a-d) Two views of mammary epithelial preselection cells (original magnifications: panels a and c, 40x; panels $b$ and d, 100x). Cells shown in panel a grow as compact clusters and are relatively uniform, whereas cells in panel b grow more dispersed and exhibit different types of cells (small and large). (e,f) Views of postselection human mammary epithelial cells with relatively uniform morphology (original magnifications: panel e, 40x; panel f, 100x).

inhibitor [24,25], and gain expression of cyclo-oxygenase (COX)-2, a gene that is thought to be involved in tumorigenesis [28]. As both of these genes are implicated in oncogenesis, it is conceivable that loss of p16 or gain of COX-2 expression may make these cells more susceptible to transformation, although it is unclear whether the loss of p16 and gain of COX-2 occur de novo during self-selection or represent selection of a minor population of cells with preexisting high COX-2 and low p16 expression. Notably, p16negative and COX-2-positive cells could be detected using immunohistochemistry in normal mammary tissue $[28,29]$.

\section{Immortalization of various HMEC subtypes in culture}

As alluded to above, normal mammoplasty-derived HMECs exhibit a limited life span, which is followed by replicative senescence. Replicative senescence acts as a strong tumor suppressor mechanism and prevents spontaneous immortalization of human cells [30-33]. A major determinant of replicative senescence is the enzyme telomerase, which maintains the length of telomere ends [30,31]. Most somatic cells express little or no telomerase, resulting in telomere shortening with successive cell divisions, which eventually elicits a senescence checkpoint [30-32]. A senescence-like phenotype can also be induced by a variety of nontelomeric signals such as DNA-damaging agents, adverse cell culture conditions, and overexpression of certain oncogenes [30,32]. The tumor suppressor protein p53 and its target gene product $\mathrm{p} 21$, and $\mathrm{p} 16^{\mathrm{INK} 4 \mathrm{a}}$ play a crucial role in senescence 
induced by telomeric as well as nontelomeric signals [30-33]. Much of our knowledge about senescence comes from studies conducted in human fibroblasts [30-34]. Only recently have we begun to elucidate the mechanisms of senescence in epithelial cells, in particular in HMECs [25].

The senescence associated with the 'selection' phase in HMEC cultures is accompanied by classic features of senescence, such as flat morphology, presence of vacuoles, and positive staining for senescence-associated $\beta$-galactosidase (SA- $\beta$-gal), a marker of senescence [34]. The block in cell proliferation at this stage is dependent on the $p R b / p 16$ pathway [24,35], because the human papillomavirus (HPV) oncogene E7, which binds and inactivates $\mathrm{pRb}$, can overcome the $\mathrm{MO} /$ selection stage [36]. Similarly, a constitutively active p16-insensitive CDK4 mutant can overcome the M0 stage [37]. Thus, senescence of preselection cells appears to be telomere independent. At the end of their replicative life span, postselection HMECs exhibit senescence as well as cell death with a high level of genomic instability. This phenomenon is termed as agonescence, as opposed to replicative senescence [25]. Most importantly, unlike rodent cells, human HMECs derived from reduction mammoplasties or from milk do not exhibit spontaneous immortalization and thus provide suitable models of human cell transformation. Immortalization of HMECs in culture is characterized by their continuous growth beyond the agonescence checkpoint. It is thought that immortalization is an early step in human cancer, and continued proliferation of immortal cells allows the accumulation of additional genetic changes that promote malignant and metastatic behavior.

Stampfer and Bartley [38] presented initial evidence that HMECs could be immortalized in cell culture using benzo(a)pyrene; however, the immortalization was a rare event in this case. Similar to carcinogen-induced immortalization, we found that $\gamma$-radiation induced the transformation of HMECs relatively infrequently $[5,8,39]$. In general, most viral oncogenes (including SV40 T antigen, adenovirus E1A and E1B, polyoma $T$ antigen) have not proven very efficient as immortalizing genes for human cells [40]. While the introduction of the SV40 $\mathrm{T}$ antigen into breast tumor tissue-derived epithelial cells gave rise to immortal cell lines, SV40-transfected cells go through a long crisis period, and emergence of immortal cells is rare [19]. Over the past several years, our studies have defined a system to immortalize human HMECs efficiently and reproducibly, using the urogenital carcinoma-associated HPV oncogenes E6 and E7 [5,8,36].

Comparison of early (preselection) and late-passage (postselection) cultures revealed that different HMEC subtypes exhibit a remarkably distinct susceptibility to E6 or E7, or their combination [8]. One HMEC subtype was exclusively immortalized by E6 but not by E7; such cells predominated the late-passage cultures but were rare at early passages. passages of tissue-derived cultures, showed extension of life span and infrequent immortalization by E7 alone. Finally, E6 and E7 together were required to immortalize fully a large proportion of preselection HMECs [8].

Human milk is an easily available source of relatively pure HMECs that are thought to be differentiated luminal cells $[2,19]$. However, these cells can be cultured for only a limited number of passages (typically two to three passages, or five to nine PDs), which has precluded their detailed biochemical study $[2,18]$. Most of the work on milk cells has been carried out in Taylor-Papadimitriou's laboratory and has demonstrated that these cells can be immortalized by SV4O T antigen [41]. Interestingly, neither E6 nor E7 alone could induce the immortalization of milk-derived HMECs, whereas a combination of E6 and E7 was effective [8].

The reproducibility and relatively high efficiency with which E6 (in postselection HMECs) or E6 and E7 combined can induce immortalization of human HMECs have therefore yielded a practical approach to elucidate the biochemical mechanisms of HMEC immortalization. In recent years, using Yeast Two-hybrid analysis, we identified several novel targets of the E6 oncogene in HMECs. These targets represent novel mediator of HMEC immortalization [5]. These include ADA3 (alteration/deficiency in activation 3), a novel coactivator of p53 and steroid receptors (estrogen receptor $[E R]$ and retinoic acid receptor) [42-44]; E6 targeted protein 1 (E6TP1), a novel GTPase activating Rap small G protein; and protein kinase $N(P K N)$, an effector for Rho small $G$ protein [5]. We recently found that MamL1, a human homolog of the Drosophila mastermind gene and a known coactivator for Notch [45], also interacts with E6 (I Bhat, V Band, unpublished data). These studies have implicated the p53, Notch, ER, Rho, and Rap signaling pathways in early transformation of human HMECs. Consistent with these analyses, we have shown that expression of mutant p53 [46] or activated Rho (X Zhao, V Band, unpublished data) induces immortalization of HMECs. Furthermore, several studies support a role for p53 mutations as an early event in breast cancer [47]. Taken together, these studies demonstrate that $E 6$ is the most efficient immortalizing gene for postselection HMECs and that E6 immortalizes the HMECs by concurrently altering multiple biochemical pathways. Future studies will need to address the precise role played by these novel oncogene targets in early breast cancer.

In addition to viral oncogenes, alterations in the expression of cellular genes can also help to overcome senescence and promote HMEC immortalization. Among the cellular genes, we recently reported that $\mathrm{Bmi}-1$, a member of the polycomb group of transcriptional repressors, could immortalize postselection HMECs [48]. Although the detailed mechanism of immortalization induced by Bmi-1 remains to be explored, Bmi-1 does not appear to immortalize these cells by downregulating the INK4a/ARF locus. Interestingly, recent studies have implicated $\mathrm{Bmi}-1$ in stem cell function and renewal 
$[49,50]$, suggesting that Bmi-1 could function as a potential breast cancer stem cell marker [50]. Another study showed that ZNF217, a zinc finger protein that is overexpressed in breast cancers, can promote immortalization of postselection HMECs [51]. Furthermore, introduction of hTERT also induces immortalization of postselection cells [5]. Interestingly, induction of telomerase has been documented early after E6 was introduced into HMECs [52], although the cause and effect relationship between telomerase induction and E6-induced immortalization continues to be debated. Recently, the E6 and E6-AP binding protein NFX-91 was implicated in E6-mediated induction of telomerase [53].

\section{Cell culture models of full transformation of HMECS}

The ability of researchers to establish normal HMECs and to induce their reproducible immortalization has provided momentum for further efforts to define the nature of biochemical alterations that can lead to full oncogenic transformation. As we and others have demonstrated, HMECs immortalized by most currently known procedures (such as E6 or E6 plus E7, mutant p53, Bmi-1 and hTERT) are preneoplastic and do not grow in an anchorageindependent manner or produce tumors when implanted in immune-deficient mice [5,8]. Weinberg and colleagues [9] recently established a multistep model of full HMEC transformation in cell culture by serial introduction of SV40 large $\mathrm{T}$ and small t, hTERT, and activated Ras (Fig. 4). It was shown that introduction of the SV40 large T, which binds and inactivates p53 and pRb, abolished senescence, whereas hTERT was needed to promote immortalization [9]. Notably, these studies showed an essential role for the SV40 small t, which inhibits protein phosphate 2A [54]. HMECs transformed by this method exhibited anchorage independence and produced poorly differentiated carcinoma (but not adenocarcinoma) when implanted in nude mice [9]. Further dissection of the role of small $t$ revealed the importance of the downstream targets of phosphatidylinositol 3-kinase, Akt1 and Rac1, and direct activation of these pathways could fully substitute for small $t$ in the transformation assays [10]. A recent refinement of the transformation in cell culture scheme suggests that perturbation of p53, $\mathrm{pRb}$, protein phosphate $2 \mathrm{~A}$, telomerase, Raf, and Ral guanine nucleotide exchange factor (Ral-GEF) pathways are required for the full tumorigenic conversion of normal human cells [11]. The requirement in terms of modulating Raf and Ral-GEF pathways is cell type specific; HMECs require activation of Raf, phosphatidylinositol 3-kinase and Ral-GEFs, whereas human fibroblasts require the activation of Raf and Ral-GEFs [11]. Thus, serial use of viral and/or cellular genes is beginning to unravel the various combinations of genetic lesions that can convert a completely normal mammary epithelial cell into a fully tumorigenic one.

Although these studies have thus far relied on the use of known oncogenes, future studies using the cell culture
Figure 4

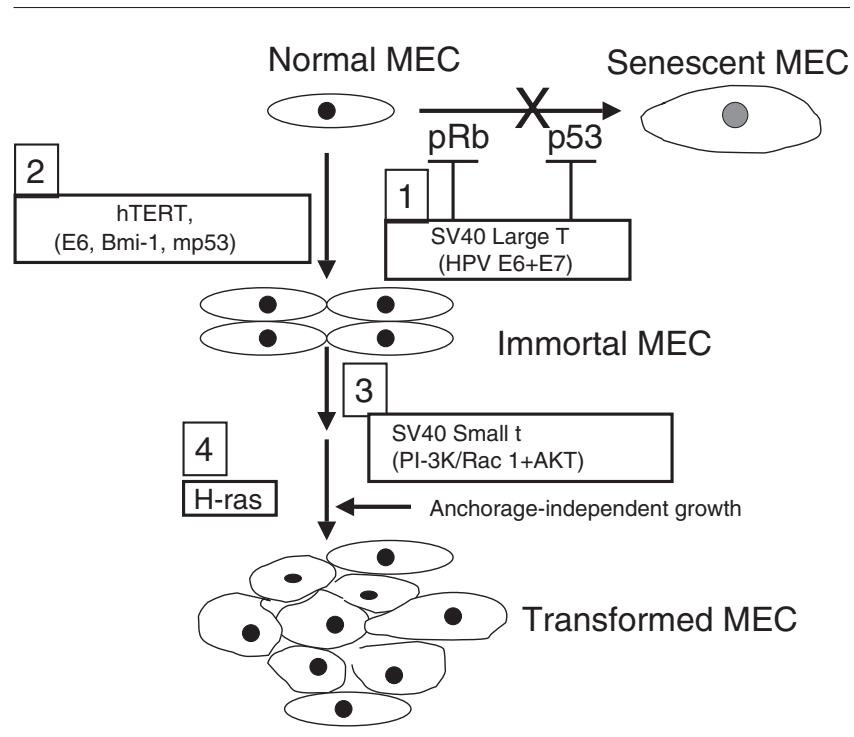

Current consensus: normal HMECs can be fully transformed in definable serial steps. The first step, bypass of senescence, is achieved by inactivation of $\mathrm{p} 53$ and $\mathrm{pRb}$ by SV40 large T, human papillomavirus (HPV) E6 and E7, or by inhibition of p53 and pRb expression by the RNAi approach (or expression of dominant-negative mutants in the case of p53). The second step, immortalization, is achieved through the expression of hTERT. Alternatively, expression of HPV E6 or overexpression of Bmi-1, mutant p53, or ZNF217 can be used to induce immortalization of HMECs. The third step, anchorageindependent growth, can be achieved by SV 40 small $t$ mediated modulation of $\mathrm{PI} 3 \mathrm{~K}$ and/or other signaling pathways or by overexpression of activated Rac1 and AKT. The fourth step, full transformation, requires the introduction of activated $\mathrm{H}$-ras, which can be substituted by Raf and Ral-GEFs. Although the current model systems have utilized the serial schemes depicted, other combinations and/or schemes of oncogene introduction are likely also to be effective. Adapted from Elenbaas [9], Zhao [10], and Rangarajan [11] and coworkers. HMEC, human mammary epithelial cell; HPV, human papillomavirus; hTERT, catalytic subunit of human telomerase; PI3K, phosphatidylinositol 3-kinase; Ral-GEF, Ral guanine nucleotide exchange factor; RNAi, RNA interference.

transformation models with gene libraries should help identify novel cellular genes that participate at various steps of breast cancer progression. Vast majority of human breast cancers are adenocarcinomas, and only a small portion of breast cancers are poorly differentiated carcinomas. Hence, it appears that HMEC transformation in culture system is not optimal because the tumors produced by these transformed HMECs have usually been poorly differentiated carcinomas rather than adenocarcinomas. Breast cancer is associated with overexpression of various cellular proto-oncogenes such as ErbB2, epidermal growth factor receptor, Src family kinases, Bmi-1, cyclin $D_{1}$, cyclin E, CDK4, and other potential growth regulators. Use of these oncogenes in the multistep model described above and the use of other HMEC subtypes (such as luminal cells, potential stem cells, or those derived from milk) as a starting population may help to achieve full transformation of HMECs that develop into adenocarcinomas 
in a nude mouse model. Thus, future studies must focus on developing models that will lead to breast tumors that faithfully reproduce the pathological characteristics of human breast cancers.

\section{Transgenic mouse models of breast cancers}

Mouse models of breast cancers have provided a wealth of knowledge about the molecular pathways involved in breast cancers. Initial studies in these models used carcinogens to induce breast carcinomas [55]. Later studies targeted a wide variety of genes expressed under either the MMTV (mouse mammary tumor virus) or the WAP (whey acidic protein) promoter to target genes to the mammary gland. Importantly, such studies invariably produced breast adenocarcinomas in mice that resembled human breast cancers. These include viral proteins, such as SV40 large T, polyoma virus T antigen [56-58], or cellular proteins such as c-Myc, ErbB2/neu, cyclin $\mathrm{D}_{1}$, cyclin E, ERs, mutant p53, c-Ha-ras, and Wnt-1 [59-63]. Recent studies have focused on mouse models with either a global or a mammary-specific knockout of specific genes to examine the function of obvious players, such as cell cycle related proteins and tumor suppressors, either by themselves or after these deficiencies were combined with transgenic neu or other oncogenes. For example, cyclin $D_{1}$-deficient mice are resistant to mammary carcinomas induced by c-neu/ ErbB2 and Ha-ras but not to those induced by c-Myc or Wnt-1 [63]. These findings define a pivotal role for cyclin $D_{1}$ in selective mammary cancers in a mouse model and imply a functional role for cyclin $D_{1}$ overexpression in a subset of human breast cancers. In another study, Cre-mediated deletion of exons 3 and 4 of the mouse Brca2 gene in mice with a loxP-modified and null Brca2 allele resulted in high incidence of breast adenocarcinomas [64]. Similarly, the telomere attrition in aging telomerase-deficient and p53mutant mice promoted the development of breast adenocarcinomas [65]. Another study showed that loss of Stat5a delays mammary cancer progression in a WAP-TAg transgenic mouse model [66].

Collectively, these models have defined a role for $\mathrm{p} 53$, pRb, BRCA1/2, cyclins, CDKs, ErbB2, c-Myc, Wnt-1, ER, and progesterone receptor in mammary cell growth and development of breast cancers. Finally, these different oncogenes and the pathways in which they work seem to target different progenitors or cell types in mammary gland to develop mammary tumors [67]. For example, the Wnt signaling pathway targets both luminal and myoepithelial cells, whereas Neu, H-Ras, and polyoma $\mathrm{T}$ antigen target only luminal epithelial cells [67]. The take-home lesson here is that the majority of these mouse models result in tumors that resemble human breast adenocarcinomas pathologically. The lack of development of adenocarcinomas from cells transformed in culture models may thus reflect the cell type that was used as the starting normal cell, rather than any peculiarity associated with the use of mouse as a host.

\section{Molecular classification of breast cancers: cues from cell culture studies}

A vast body of clinical literature indicates that breast tumors exhibit diverse phenotypes as judged by their distinct clinical course, pathological features, and responsiveness to various therapies. However, it has not been clear whether this diversity reflects cancers arising from distinct subtypes of HMECs. Consistent with such a possibility, several years ago we reported the presence of different subtypes of cells in reduction mammoplasty specimens and in milk that exhibited differential susceptibility to viral oncogenes $[5,8]$. Direct evidence for the conclusions derived from these cell culture studies was provided by recent work utilizing gene expression patterns in primary human breast cancers, using cDNA microarrays. These studies identified distinct gene expression profiles or molecular portraits based on which breast tumors could be subclassified into groups that appear to reflect the original cellular subtypes found in the mammary gland [12]. Five categories of breast cancers were described [12]: a basal epithelial-like group, an ErbB2-overexpressing group, a normal breast epithelial-like group, luminal epithelial cell type A, and luminal epithelial cell type B. A slightly different classification was proposed by Sotiriou and coworkers [68]. The breast tumors were first divided into ERpositive and ER-negative categories. The ER-negative tumors were further subgrouped into basal-like 1, basal-like 2, and ErbB2/neu tumors, whereas ER-positive tumors were subdivided into luminal-like 1, luminal-like 2, and luminal-like 3 subtypes. Sotiriou and coworkers also re-examined data from the study by Sorlie and coworkers [12] and suggested that luminal-like breast cancer could be classified as luminal $A, B$, and $C$ subtypes corresponding to luminal-like 1 , luminal-like 2 , and luminal-like 3 subtypes.

Interestingly, survival analyses conducted in a subcohort of patients with locally advanced breast cancer uniformly treated in a prospective study showed significantly different outcomes for the patients belonging to the various groups, with the basal-like subtype correlating with worst outcome, followed by ErbB2 overexpressing, normal cell type and luminal cell type groups $[12,68]$. Interestingly, a significant difference in outcome for the two ER-positive groups was also noticed [68]. These studies strongly support the idea that many of the breast tumor subtypes may represent malignancies of biologically distinct cell types producing distinct disease entities that may require different treatment strategies. Importantly, these analyses provide a strong rationale for further definition of various mammary epithelial subtypes and expansion of immortalization and full transformation strategies to derive models that may faithfully reproduce the histological and molecular diversity encountered in human breast cancers.

\section{Do breast cancers arise from stem cells?}

Stem cells have enormous replicative potential and capacity for self-renewal, and give rise to different lineages of cells. 
Although still a controversial notion, many cancers are thought to originate from cancer stem cells [69]. This idea has also attracted a great interest in the field of breast cancer research, and investigators have begun to examine whether there are mammary stem cells $[13,17,27,70-73]$. The cellular milieu of the mammary gland undergoes significant changes during pregnancy, lactation, and involution. These include bursts of proliferation of existing cells during pregnancy, continued differentiation during lactation, and apoptosis during involution at the end of the cycle. This cyclical behavior predicts the presence of a stem cell-like population in the mammary gland, which would meet the demand of a pregnancy cycle. The existence of adult mammary epithelial stem cells has therefore been proposed. Direct evidence for the existence of such cells has come from clear fat-pad transplantation, retroviral tagging, and X-chromosome inactivation studies in rodent model [13,16,17,70-73].

Recently, using various putative stem cell and cell surface markers, such as sialomucin (Muc), epithelial-specific antigen (ESA), various cytokeratins, ASMA, and CALLA or CD10, attempts have been made to identify the mouse and human mammary epithelial stem cells [13,27,70-73]. Using immunomagnetic cell sorting based on surface antigen markers (Muc and ESA) and subsequent immortalization with E6 and E7, Gudjonsson and coworkers [27] separated $\mathrm{Muc}^{-} / \mathrm{ESA}^{+/}$ $\mathrm{K}-19^{+}$cells that were able both to self-renew and to give rise to $\mathrm{Muc}^{-} / \mathrm{ESA}^{+}$epithelial cells and $\mathrm{ASMA}^{+}$myoepithelial cells, thus exhibiting characteristic of breast stem cells. Dontu and coworkers [13] isolated undifferentiated mammospheres from single cell suspensions of HMECs obtained by mechanical and enzymatic dissociations. Primary mammospheres can be further passaged to generate secondary mammospheres. Primary as well as secondary mammospheres were highly enriched in early progenitor or stem cells capable of differentiating along multiple lineages and of selfrenewal. Immunostaining of these mammospheres showed the presence of CD10, $\alpha_{6}$ integrin and K-5 on early progenitors, and ESA and K-14 on late progenitor cells [13]. However, MUC1, K-18, and ASMA were not expressed in cells present in mammospheres [13]. Detailed expression profiling of mammospheres suggests the presence of additional markers that are upregulated in mammospheres such as stem cell growth factor, hepatocyte growth factor antagonist, stem cell growth factor B and apolipoprotein E. Some markers are exclusively expressed in mammospheres such as FZD2 (frizzled homolog 2), glypican 4, interleukin-6, CXCR4 (CXC chemokine receptor), and FGFR1 (fibroblast growth factor receptor 1 ). Several genes that are expressed in mammospheres are also expressed in similar structures derived from other cell types (such as neurospheres formed by neural stem cells) [13].

Thus, culture of human HMECs in mammospheres may provide a tool with which to isolate and study mammary epithelial stem cells and their oncogenic susceptibilities.
Based on the above and other related studies [13,17,27], the candidate mammary stem cells appear to be $\mathrm{ESA}^{+}, \mathrm{MUC1}^{-}$, $\alpha_{6}$ integrin $^{+}$, and $\mathrm{CD}^{+} 0^{+}$, and the mammary stem cell niche appears to be at the suprabasal location within the luminal cell layer. Further work by other laboratories and adoption of the schemes employed by Gudjonsson [27] and Dontu [13] and their groups should help in determining the general feasibility of these novel approaches.

Apart from normal mammary stem cells, the possible existence of a breast cancer stem cell has been reported in the literature $[74,75]$. In a NOD/SCID xenotransplants model, Al-Hajj and coworkers [75] used four cell surface markers, CD44, CD24, ESA and B38.1 (a Breast/ovarian cancer specific marker), and lineage markers to sort different populations of breast cells from breast tumor tissues. All mice injected with $\mathrm{Lin}^{-} / \mathrm{CD} 44^{+} / \mathrm{B} 38.1^{+} / \mathrm{CD} 24^{-/ \text {low }}$ generated tumors, whereas none of the mice injected with $\mathrm{CD} 44^{-} /$ B38.1- cells developed tumors. Lin-/CD44+/B38.1+ fractions were further subdivided based on ESA expression. When used in numbers as low as 200, Lin $^{-} / \mathrm{ESA}^{+} / \mathrm{CD}_{4} 4^{+} /$ CD24-/low cells in xenotransplants generated tumors that were similar to initial tumors in term of phenotypic heterogeneity [75]. The presence of such a population in breast tumor tissue, which is able to self-renew and differentiate, supports the stem-cell model of breast tumorigenesis.

\section{Conclusion}

Our ability to culture and immortalize normal HMECs has provided a wealth of knowledge about the behavior of mammary cells and the genes involved in normal cell growth and oncogenesis. Characterization of these cells has provided novel markers that may permit early diagnosis and prognosis of breast cancers, and has yielded knowledge about potential precursor cells for breast cancers. Transformation analyses in cell culture models have also proven important to our understanding of the multistep nature of breast cancer. Transgenic mouse models have identified the roles played by various tumor suppressors, cell cycle proteins, and other protooncogenes in breast cancers. Recent studies using threedimensional models have proven useful to our understanding of the normal and tumor mammary stem cells and the relationship of microenvironment to epithelial cell growth. Finally, using gene profiling, we have begun to appreciate that breast cancers do not originate only from luminal cells but also from basal and myoepithelial cells, and that there are subtypes of breast cancers that possibly originate from distinct normal precursors that have distinct clinical outcomes and may require different treatment strategies.

However, a number of critical questions remain. What are breast stem cells and what is their role in breast cancer? Are myoepithelial cells and basal cells similar or distinct? Why can we not culture most of the primary breast cancers? How can we develop transformed breast cells in culture that would give rise to breast tumors that resemble human breast cancer - 
adenocarcinomas as opposed to poorly differentiated carcinomas? How do different subtypes of breast cancer originate?

In conclusion, experimental immortalization and transformation models have led to substantial progress in our understanding of the biology of breast cancer. Future studies in these model systems should go a long way toward elucidating the nature of breast cancer heterogeneity and thus facilitate the development of more individualized therapies for breast cancer patients.

\section{Competing interests}

The author(s) declare that they have no competing interests.

\section{Acknowledgments}

We apologize to many of our colleagues whose original work could not be cited due to space constrains.

We thank past and present members of our respective laboratories for their contribution to work published from our laboratories. Work in our laboratories was supported by the NIH Grants CA94143, CA96844, CA81076, and DAMD BC010093 (VB); CA 87986, CA 76118, CA 99900, CA99163, and DAMD17-02-1-0303 (HB); and CA 094150 and DAMD17-02-1-0509 (GD). VB and HB gratefully acknowledge the support of the Duckworth Family Chair in Breast Cancer Research and Jean Ruggles-Romoser Chair for Cancer Research, respectively.

\section{References}

1. Jemal A, Murray T, Ward E, Samuels A, Tiwari RC, Ghafoor A, Feuer EJ, Thun MJ: Cancer statistics, 2005. CA Cancer J Clin 2005, 55:10-30.

2. Taylor-Papadimitriou J, Berdichevsky F, D'Souza B, Burchell J: Human models of breast cancer. Cancer Surv 1993, 16:59-78.

3. Farber E: The multistep nature of cancer development. Cancer Res 1984, 44:4217-4223.

4. Hanahan D, Weinberg RA: The hallmarks of cancer. Cell 2000, 100:57-70.

5. Ratsch SB, Gao Q, Srinivasan S, Wazer DE, Band V: Multiple genetic changes are required for efficient immortalization of different subtypes of normal human mammary epithelial cells. Radiat Res 2001, 155:143-150.

6. Ethier SP, Summerfelt RM, Cundiff KC, Asch BB: The influence of growth factors on the proliferative potential of normal and primary breast cancer-derived human breast epithelial cells. Breast Cancer Res Treat 1991, 17:221-230.

7. Yaswen P, Stampfer MR: Molecular changes accompanying senescence and immortalization of cultured human mammary epithelial cells. Int J Biochem Cell Biol 2002, 34: 1382-1394.

8. Wazer DE, Liu XL, Chu Q, Gao Q, Band V: Immortalization of distinct human mammary epithelial cell types by human papilloma virus 16 E6 or E7. Proc Natl Acad Sci USA 1995, 92: 3687-3691.

9. Elenbaas B, Spirio L, Koerner F, Fleming MD, Zimonjic DB, Donaher JL, Popescu NC, Hahn WC, Weinberg RA: Human breast cancer cells generated by oncogenic transformation of primary mammary epithelial cells. Genes Dev 2001, 15:50-65.

10. Zhao JJ, Gjoerup OV, Subramanian RR, Cheng Y, Chen W, Roberts TM, Hahn WC: Human mammary epithelial cell transformation through the activation of phosphatidylinositol 3kinase. Cancer Cell 2003, 3:483-495.

11. Rangarajan A, Hong SJ, Gifford A, Weinberg RA: Species- and cell type-specific requirements for cellular transformation. Cancer Cell 2004, 6:171-183.

12. Sorlie T, Tibshirani R, Parker J, Hastie T, Marron JS, Nobel A, Deng S, Johnsen H, Pesich R, Geisler S, et al.: Repeated observation of breast tumor subtypes in independent gene expression data sets. Proc Natl Acad Sci USA 2003, 100:8418-8423.

13. Dontu G, Abdallah WM, Foley JM, Jackson KW, Clarke MF, Kawamura MJ, Wicha MS: In vitro propagation and transcriptional profiling of human mammary stem/progenitor cells. Genes Dev 2003, 17:1253-1270.

14. Schmeichel KL, Bissell MJ: Modeling tissue-specific signaling and organ function in three dimensions. J Cell Sci 2003, 116: 2377-2388.

15. Allinen $\mathrm{M}$, Beroukhim $\mathrm{R}$, Cai L, Brennan C, Lahti-Domenici J, Huang H, Porter D, Hu M, Chin L, Richardson A, et al:: Molecular characterization of the tumor microenvironment in breast cancer. Cancer Cell 2004, 6:17-32.

16. Cardiff RD, Wellings SR: The comparative pathology of human and mouse mammary glands. J Mammary Gland Biol Neoplasia 1999, 4:105-122.

17. Smalley M, Ashworth $A$ : Stem cells and breast cancer: a field in transit. Nat Rev Cancer 2003, 3:832-844.

18. Lakhani SR, O'Hare MJ: The mammary myoepithelial cell - Cinderella or ugly sister? Breast Cancer Res 2001, 3:1-4.

19. Taylor-Papadimitriou J, Stampfer M, Bartek J, Lewis A, Boshell M, Lane EB, Leigh IM: Keratin expression in human mammary epithelial cells cultured from normal and malignant tissue: relation to in vivo phenotypes and influence of medium. $J$ Cell Sci 1989, 94:403-413.

20. Band V, Sager R: Distinctive traits of normal and tumorderived human mammary epithelial cells expressed in a medium that supports long-term growth of both cell types. Proc Natl Acad Sci USA 1989, 86:1249-1253.

21. Petersen OW, Ronnov-Jessen L, Howlett AR, Bissell MJ: Interaction with basement membrane serves to rapidly distinguish growth and differentiation pattern of normal and malignant human breast epithelial cells. Proc Natl Acad Sci USA 1992, 89:9064-9068.

22. Janss DH, Hillman EA, Malan-Shibley LB, Ben TL: Methods for the isolation and culture of normal human breast epithelial cells. Methods Cell Biol 1980, 21B:107-135.

23. Easty GC, Easty DM, Monaghan P, Ormerod MG, Neville AM: Preparation and identification of human breast epithelial cells in culture. Int J Cancer 1980, 26:577-584.

24. Wong DJ, Foster SA, Galloway DA, Reid BJ: Progressive regionspecific de novo methylation of the $\mathrm{p} 16 \mathrm{CpG}$ island in primary human mammary epithelial cell strains during escape from M(0) growth arrest. Mol Cell Biol 1999, 8:5642-5651.

25. Romanov SR, Kozakiewicz BK, Holst CR, Stampfer MR, Haupt LM, Tlsty TD: Normal human mammary epithelial cells spontaneously escape senescence and acquire genomic changes. Nature 2001, 409:633-637.

26. Trask DK, Band V, Zajchowski DA, Yaswen P, Suh T, Sager R: Keratins as markers that distinguish normal and tumorderived mammary epithelial cells. Proc Natl Acad Sci USA 1990, 87:2319-2323.

27. Gudjonsson T, Villadsen R, Nielsen HL, Ronnov-Jessen L, Bissell MJ, Petersen OW: Isolation, immortalization, and characterization of a human breast epithelial cell line with stem cell properties. Genes Dev 2002, 16:693-706.

28. Crawford YG, Gauthier ML, Joubel A, Mantei K, Kozakiewicz K, Afshari CA, TIsty TD: Histologically normal human mammary epithelia with silenced p16(INK4a) overexpress COX-2, promoting a premalignant program. Cancer Cell 2004, 5:263-273.

29. Holst CR, Nuovo GJ, Esteller M, Chew K, Baylin SB, Herman JG, Tlsty TD: Methylation of p16(INK4a) promoters occurs in vivo in histologically normal human mammary epithelia. Cancer Res 2003, 63:1596-1601.

30. Itahana K, Campisi J, Dimri GP: Mechanisms of cellular senescence in human and mouse cells. Biogerontology 2004, 5:1-10.

31. Shay JW, Wright WE: Senescence and immortalization: role of telomeres and telomerase. Carcinogenesis 2005, 26:867-874.

32. Ben-Porath I, Weinberg RA: When cells get stressed: an integrative view of cellular senescence. J Clin Invest 2004, 113:813.

33. Itahana K, Dimri G, Campisi J: Regulation of cellular senescence by p53. Eur J Biochem 2001, 268:2784-2791.

34. Dimri GP, Lee X, Basile G, Acosta M, Scott G, Roskelley C, Medrano EE, Linskens M, Rubelj I, Pereira-Smith O, et al:: A biomarker that identifies senescent human cells in culture and in aging skin in vivo. Proc Natl Acad Sci USA 1995, 92:9363-9367.

35. Brenner AJ, Stampfer MR, Aldaz CM: Increased $\mathrm{p} 16$ expression with first senescence arrest in human mammary epithelial cells and extended growth capacity with p16 inactivation. Oncogene 1998, 17:199-205. 
36. Boyer SN, Wazer DE, Band V: E7 protein of human papilloma virus-16 induces degradation of retinoblastoma protein through the ubiquitin-proteasome pathway. Cancer Res 1996, 56:4620-4624.

37. Ramirez RD, Herbert BS, Vaughan MB, Zou Y, Gandia K, Morales $\mathrm{CP}$, Wright WE, Shay JW: Bypass of telomere-dependent replicative senescence (M1) upon overexpression of Cdk4 in normal human epithelial cells. Oncogene 2003, 22:433-444.

38. Stampfer MR, Bartley JC: Induction of transformation and continuous cell lines from normal human mammary epithelial cells after exposure to benzo [A]pyrene. Proc Natl Acad Sci USA 1985, 82:2394-2398.

39. Wazer DE, Chu Q, Liu XL, Gao Q, Safaii H, Band V: Loss of p53 protein during radiation transformation of primary human mammary epithelial cells. Mo/ Cell Biol 1994, 14:2468-2478.

40. Toouli CD, Huschtscha LI, Neumann AA, Noble JR, Colgin LM, Hukku B, Reddel RR: Comparison of human mammary epithelial cells immortalized by simian virus $40 \mathrm{~T}$-antigen or by the telomerase catalytic subunit. Oncogene 2002, 21:128-139.

41. Bartek J, Bartkova J, Kyprianou N, Lalani EN, Staskova Z, Shearer $\mathrm{M}$, Chang S, Taylor-Papadimitriou J: Efficient immortalization of luminal epithelial cells from human mammary gland by introduction of simian virus 40 large tumor antigen with a recombinant retrovirus. Proc Natl Acad Sci USA 1991, 88: 3520-3524.

42. Kumar A, Zhao Y, Meng G, Zeng M, Srinivasan S, Delmolino LM, Gao Q, Dimri G, Weber GF, Wazer DE, et al:: Human papillomavirus oncoprotein E6 inactivates the transcriptional coactivator human ADA3. Mol Cell Biol 2002, 22:5801-5812.

43. Zeng M, Kumar A, Meng G, Gao Q, Dimri G, Wazer D, Band H, Band V: Human papilloma virus 16 E6 oncoprotein inhibits retinoic $X$ receptor-mediated transactivation by targeting human ADA3 coactivator. J Biol Chem 2002, 277:4561145618.

44. Meng G, Zhao Y, Nag A, Zeng M, Dimri G, Gao Q, Wazer DE, Kumar $R$, Band $H$, Band $V$ : Human ADA3 binds to estrogen receptor (ER) and functions as a coactivator for ER-mediated transactivation. J Biol Chem 2004, 279:54230-54240.

45. Wu L, Aster JC, Blacklow SC, Lake R, Artavanis-Tsakonas S, Griffin JD: MAML1, a human homologue of Drosophila mastermind, is a transcriptional co-activator for NOTCH receptors. Nat Genet. 2000, 26:484-489.

46. Gao Q, Hauser SH, Liu XL, Wazer DE, Madoc-Jones H, Band V: Mutant p53-induced immortalization of primary human mammary epithelial cells. Cancer Res 1996, 56:3129-3133.

47. Lukas J, Niu N, Press MF: p53 mutations and expression in breast carcinoma in situ. Am J Pathol 2000, 156:183-191.

48. Dimri GP, Martinez JL, Jacobs JL, Keblusek P, Itahana K, van Lohuizen M, Campisi J, Wazer DE, Band V: Bmi-1 oncogene induces telomerase and immortalizes human mammary epithelial cells. Cancer Res 2002, 62:4736-4745.

49. Park IK, Qian D, Kiel M, Becker MW, Pihalja M, Weissman IL, Morrison SJ, Clarke MF: Bmi-1 is required for maintenance of adult self-renewing haematopoietic stem cells. Nature 2003, 423: 302-305.

50. Lessard J, Sauvageau G: Bmi-1 determines the proliferative capacity of normal and leukaemic stem cells. Nature 2003, 423:255-260.

51. Nonet GH, Stampfer MR, Chin K, Gray JW, Collins CC, Yaswen $\mathrm{P}$ : The ZNF217 gene amplified in breast cancers promotes immortalization of human mammary epithelial cells. Cancer Res 2001, 61:1250-1254

52. Klingelhutz AJ, Foster SA, McDougall JK: Telomerase activation by the E6 gene product of human papillomavirus type 16 . Nature 1996, 380:79-82.

53. Gewin L, Myers H, Kiyono T, Galloway DA: Identification of a novel telomerase repressor that interacts with the human papillomavirus type-16 E6/E6-AP complex. Genes Dev 2004, 18:2269-2282

54. Hahn WC, Dessain SK, Brooks MW, King JE, Elenbaas B, Sabatini DM, DeCaprio JA, Weinberg RA: Enumeration of the simian virus 40 early region elements necessary for human cell transformation. Mol Cell Biol 2002, 22:2111-2123.

55. Sukumar S, McKenzie K, Chen Y: Animal models for breast cancer. Mutat Res 1995, 333:37-44.

56. Guy CT, Cardiff RD, Muller WJ: Induction of mammary tumors by expression of polyomavirus middle $\mathrm{T}$ oncogene: a trans- genic mouse model for metastatic disease. Mol Cell Biol 1992, 12:954-961.

57. Li M, Lewis B, Capuco AV, Laucirica R, Furth PA: WAP-TAg transgenic mice and the study of dysregulated cell survival, proliferation, and mutation during breast carcinogenesis. Oncogene 2000, 19:1010-1019.

58. Husler MR, Kotopoulis KA, Sundberg JP, Tennent BJ, Kunig SV, Knowles BB: Lactation-induced WAP-SV40 Tag transgene expression in C57BL/6J mice leads to mammary carcinoma. Transgenic Res 1998, 7:253-263.

59. Blackshear PE: Genetically engineered rodent models of mammary gland carcinogenesis: an overview. Toxicol Pathol 2001, 29:105-116.

60. Muller WJ, Sinn E, Pattengale PK, Wallace R, Leder P: Singlestep induction of mammary adenocarcinoma in transgenic mice bearing the activated c-neu oncogene. Cell 1988, 54: 105-115.

61. Li Y, Hively WP, Varmus HE: Use of MMTV-Wnt-1 transgenic mice for studying the genetic basis of breast cancer. Oncogene 2000, 19:1002-1009.

62. D'Cruz CM, Gunther EJ, Boxer RB, Hartman JL, Sintasath L, Moody SE, Cox JD, Ha SI, Belka GK, Golant A, et al:: c-MYC induces mammary tumorigenesis by means of a preferred pathway involving spontaneous Kras2 mutations. Nat Med 2001, 7:235-239.

63. $Y u, Q$, Geng $Y$, Sicinski P: Specific protection against breast cancers by cyclin D1 ablation. Nature 2001, 411:1017-1021.

64. Ludwig T, Fisher P, Murty V, Efstratiadis A: Development of mammary adenocarcinomas by tissue-specific knockout of Brca2 in mice. Oncogene 2001, 20:3937-3948.

65. Artandi SE, Chang S, Lee SL, Alson S, Gottlieb GJ, Chin L, DePinho RA: Telomere dysfunction promotes non-reciprocal translocations and epithelial cancers in mice. Nature 2000, 406:641-645.

66. Ren S, Cai HR, Li M, Furth PA: Loss of Stat5a delays mammary cancer progression in a mouse model. Oncogene 2002, 21: 4335-4339.

67. Li Y, Welm B, Podsypanina K, Huang S, Chamorro M, Zhang $X$, Rowlands T, Egeblad M, Cowin P, Werb Z, et al.: Evidence that transgenes encoding components of the Wnt signaling pathway preferentially induce mammary cancers from progenitor cells. Proc Natl Acad Sci USA 2003, 100:15853-15858.

68. Sotiriou C, Neo SY, McShane LM, Korn EL, Long PM, Jazaeri A, Martiat $P$, Fox SB, Harris AL, Liu ET: Breast cancer classification and prognosis based on gene expression profiles from a population-based study. Proc Natl Acad Sci USA 2003, 100: 10393-10398

69. Marx J: Cancer research. Mutant stem cells may seed cancer. Science 2003, 301:1308-1310.

70. Kordon EC, Smith $\mathrm{GH}$ : An entire functional mammary gland may comprise the progeny from a single cell. Development 1998, 125:1921-1930.

71. Smith GH, Chepko G: Mammary epithelial stem cells. Microsc Res Tech 2001, 52:190-203.

72. Stingl J, Eaves CJ, Zandieh I, Emerman JT: Characterization of bipotent mammary epithelial progenitor cells in normal adult human breast tissue. Breast Cancer Res Treat 2001, 67:93109.

73. Stingl J, Eaves CJ, Kuusk U, Emerman JT: Phenotypic and functional characterization in vitro of a multipotent epithelial cell present in the normal adult human breast. Differentiation 1998 , 63:201-213.

74. Dick JE: Breast cancer stem cells revealed. Proc Natl Acad Sci USA 2003, 100:3547-3549.

75. Al-Hajj M, Wicha MS, Benito-Hernandez A, Morrison SJ, Clarke MF: Prospective identification of tumorigenic breast cancer cells. Proc Natl Acad Sci USA 2003, 100:3983-3988. 